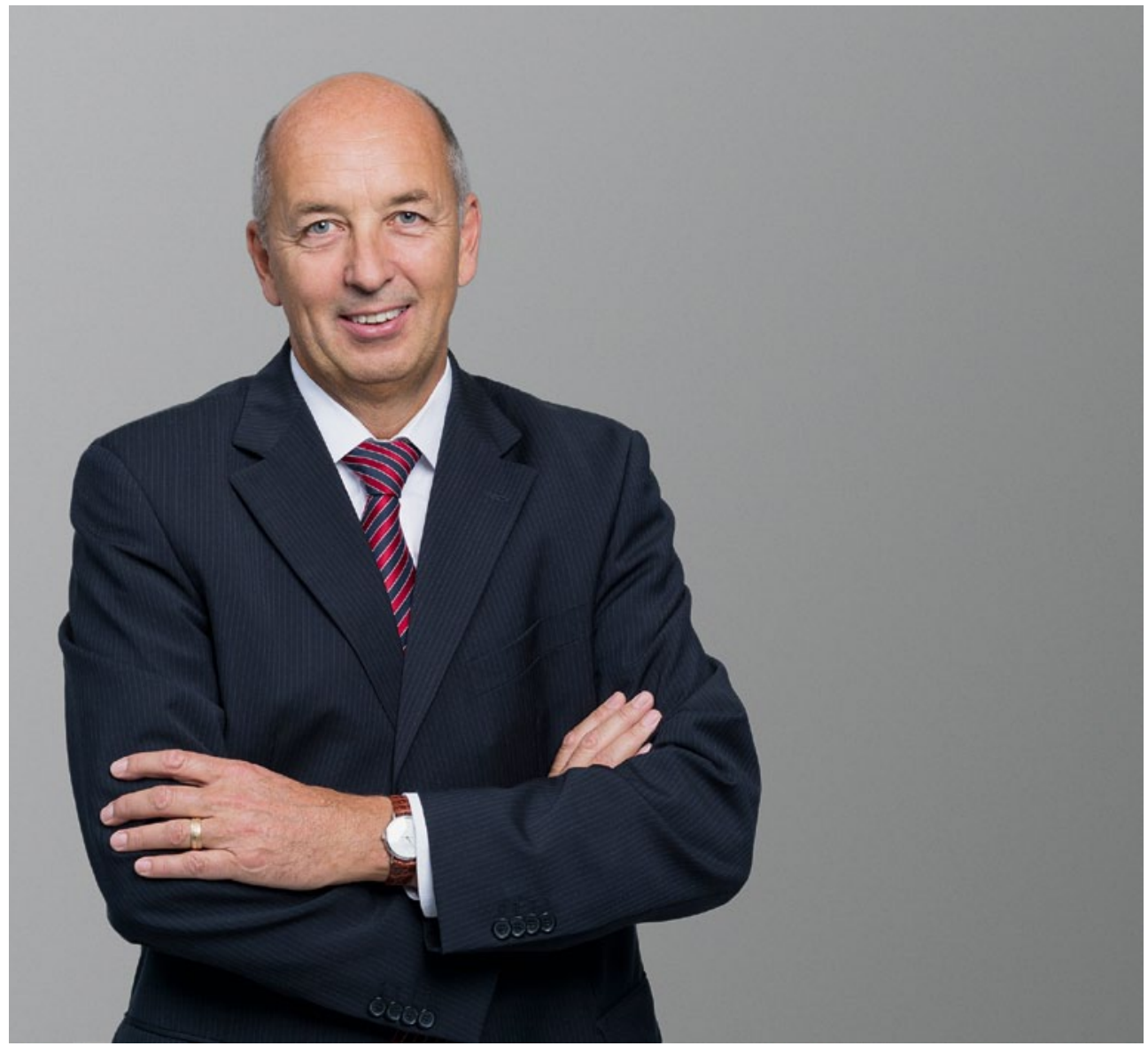

DR. RALPH-MICHAEL SCHMIDT

Geschäftsführer

L'Orange GmbH

\title{
PIONIERGEIST IN DER MOTORTECHNIK
}

Die Motortechnische Zeitschrift ist mit dem Namen L'Orange historisch und fachlich sehr eng verbunden. Prosper L’Orange, ein Pionier der Einspritztechnologie und Erfinder des Vorkammer-Prinzips, war nicht nur einer der Gründer der MTZ. Seine beiden Söhne Rudolf und Harro L'Orange haben 1933 die L'Orange $\mathrm{GmbH}$ ins Leben gerufen, damals noch unter dem Namen Gebrüder L'Orange Motorzubehör GmbH. Auf Basis von Patenten und Ideen ihres Vaters legten die Gebrüder die Grundlagen für unser heute weltweit erfolgreiches Unternehmen. Für sein Lebenswerk erhielt Prosper L'Orange einen Ehrendoktortitel im Gründungsjahr der MTZ. Neben der Herausgabe der Motortechnischen Zeitschrift gestaltete er im Sinne seiner wegweisenden Ingenieursleistungen auch aktiv die Inhalte.

Genau wie der Name L’Orange steht auch die MTZ für Pioniergeist im Bereich der Motortechnik - wenngleich als Zeitschrift mit einem im Wesentlichen rein fachlichen und wissenschaftlichen Hintergrund. Das Anliegen von Prosper L'Orange bei der Gründung der MTZ umfasste vor allem den uneingeschränkten Austausch zu Entwicklungen, Versuchen und Ideen zu den Themen Antrieb, Einspritzung und Motortechnologie über die Grenzen von rein kommerziellen Betrachtungen hinaus. Dieser Grundlage ist die MTZ bis heute treu geblieben.

Ich freue mich über das sehr umfassende Themenspektrum in der Jubiläumsausgabe. Der Weg in die Zukunft der Antriebstechnologie ist komplex und vielschichtig. Forschung und Entwicklung sind die Schlüssel zu verbrauchsarmen und emissionsoptimierten Motoren. Die L’Orange GmbH hat das erkannt und investiert seit vielen Jahren intensiv in ihre Forschungsund Entwicklungsabteilungen. Der Blick über den Tellerrand ist dabei entscheidend. Um den eigenen Horizont zu erweitern, ist ein fachlicher Austausch mit anderen Unternehmen und Branchen sinnvoll und zielführend. Die MTZ unterstützt diesen Wissenstransfer und den Informationsaustausch seit nunmehr 75 Jahren - eine wichtige Grundlage für die Entwicklung des Motors von morgen. Dafür möchte ich mich herzlich bedanken, und so wünsche ich der MTZ weiterhin erfolgreiche Jahre. 